\title{
Self Diffusion in a Glassformer Melt Oxygen Transport in Boron Trioxide
}

\author{
Taneki Tokuda, Tomoyasu Ito, and Takashi Yamaguchi \\ Tokyo Metropolitan University, Faculty of Science, Fukazawa, Setagaya, Tokyo, Japan
}

(Z. Naturforsch. 26 a, 2058-2060 [1971] ; received 1 March 1971)

\begin{abstract}
Quite a few investigations have been published on the diffusion of modifiers in glassy substances, but only a few studies have been reported on the self diffusion in a glassformer itself ${ }^{1}$. The self diffusion of oxygen in a boron trioxide melt was measured in this study.
\end{abstract}

\section{Experimental}

The gas-liquid isotope exchange $\operatorname{method}^{1}$ was employed. This method is quite useful in the relatively low temperature region. In the higher temperature region, the capillary method gives better results ${ }^{2}$. Oxygen, carbon monoxide, carbon dioxide and many other oxygen containing gases can be used as an isotope exchange gas. Carbon dioxide gas was used in this study because the exchange reaction occured more easily for carbon dioxide than for other gases and mass spectrometric analysis was most reliable for this gas.

The boron trioxide used was a commercial product made by the Kanto Chemicals Company Ltd. Through emission spectroscopy, it was elucidated that the sample contained $10 \mathrm{ppm} \mathrm{Mg}, 10 \mathrm{ppm} \mathrm{Si}$, and traces of $\mathrm{Na}$, $\mathrm{K}$, and $\mathrm{Ca}$. Argon or nitrogen gas, passed through a trap cooled by dry ice to freeze out water, was bubbled through a boron trioxide melt for $20-25 \mathrm{hr}$ at $1200^{\circ} \mathrm{C}$ to remove traces of water contained in the melt. Experimental results for diffusion indicated, as will be shown later, that $10 \mathrm{hr}$ was enough to reach equilibrium.

The boron trioxide sample, contained in a platinum dish, was held in an isotope exchange vessel made of fused quartz. The isotope exchange vessel was evacuated, and carbon dioxide gas labelled with heavy oxygen $\left(\mathrm{CO}^{18} \mathrm{O}^{16}\right)$ was introduced at about $90-110$ Torr, and maintained for several hours at experimental temperatures of $351^{\circ}-650{ }^{\circ} \mathrm{C}$. A small quantity of gas was taken out periodically and analysed mass spectrometrically for the oxygen isotope abundance ratio. If some oxygen was exchanged between the carbon dioxide gas and the boron trioxide melt and self diffusion occurred in the melt, the abundance ratio of $\mathrm{O}^{18}$ to $\mathrm{O}^{16}$ in the carbon dioxide gas should decrease according to the diffusion law. The exchange reaction of oxygen between the fused quartz vessel and carbon dioxide gas is, as is shown in Fig. 1, negligibly small compared to that between boron trioxide and carbon dioxide gas.

If the rate-determining step is not the exchange reaction, but the diffusion process in the boron tri-

1 T. Tokuda and W. D. Kingery, J. Appl. Phys. 34, 2104 [1963].

2 Unpublished.

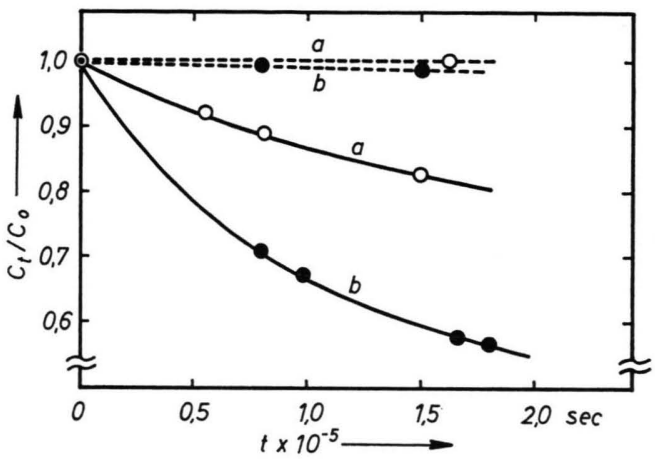

Fig. 1. Relationship between $C_{t} / C_{0}$ and $t$. Broken lines: blank test. Solid lines: experimental results with a boron trioxide sample. a: at $501{ }^{\circ} \mathrm{C} ; \mathbf{b}$ : at $601{ }^{\circ} \mathrm{C}$.

oxide melt, the decrease of the $\mathrm{O}^{18}$ content in carbon dioxide gas should obey the law ${ }^{3}$,

$$
\begin{array}{r}
\frac{C_{0}-C_{t}}{C_{0}-C_{\infty}}=\frac{M_{t}}{M_{\infty}}=1-\sum_{n=1}^{\infty} \frac{2(1+\alpha) \alpha}{1+\alpha+\alpha^{2} q_{n}{ }^{2}} \\
\cdot \exp \left\{-D q_{n}{ }^{2} t / l^{2}\right\} .
\end{array}
$$

If $D t / l^{2}$ is small enough, the following approximate equation can be employed,

$$
\begin{aligned}
M_{t} / M_{\infty}= & (1+\alpha) \\
& \cdot\left\{1-\exp \left\{D t / \alpha^{2} l^{2}\right\} \operatorname{erfc}\left\{D t / \alpha^{2} l^{2}\right\}^{1 / 2}\right\}
\end{aligned}
$$

where $C_{0}, C_{t}, C_{\infty}=$ concentrations of $\mathrm{O}^{18}$ in gas, $t=$ time for diffusion, $M_{t}=$ amount of $0^{18}$ diffused into boron trioxide melt by the time $t, M_{\infty}=$ the corresponding quantity after infinite time, $q_{n}=$ the non zero positive roots of $\tan q_{n}=-\alpha q_{n}, \alpha=\mathrm{mol}$ rato of total oxygen atoms $\left(\mathrm{O}^{18}+\mathrm{O}^{16}\right)$ in the molten boron trioxide sample to that in the carbon dioxide gas, $l=$ thickness of the molten boron trioxide sample in the platinum dish, $\operatorname{erfc}=\operatorname{erfc} Z=1-\operatorname{erf} Z$.

\footnotetext{
3 J. Crank, The Mathematics of Diffusion, Oxford at the
} Clarendon Press, Chapter 4.35, p. 52, 1964. 


\section{Results}

As is shown in Fig. 2, the plot $D t / l$ vs. $t$ is a straight line passing through the origin. Therefore, the rate-determining step is considered not to be the exchange reaction, but diffusion in the melt.

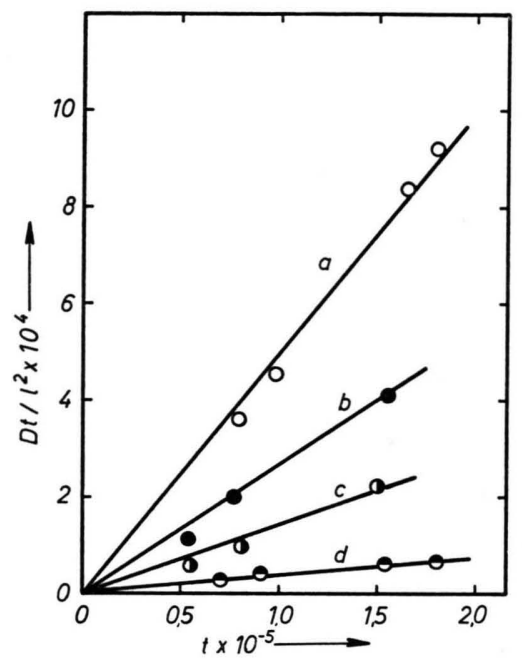

Fig. 2. Relationship between $D t / l^{2}$ and $t$. a: at $601{ }^{\circ} \mathrm{C} ;$ b: at $552{ }^{\circ} \mathrm{C} ;$ c: at $501{ }^{\circ} \mathrm{C}$; d: at $452{ }^{\circ} \mathrm{C}$.

Moreover, if the exchange reaction on the surface of the boron trioxide melt was the rate-determining step, the dependence of

$$
-\log \left\{\left(C_{t}-C_{\infty}\right) /\left(C_{0}-C_{\infty}\right)\right\} \text { on } t
$$

should be linear, and if the diffusion process was the rate-determining step, it should be curvilinear. As shown in Fig. 3, the relation was curvilinear at

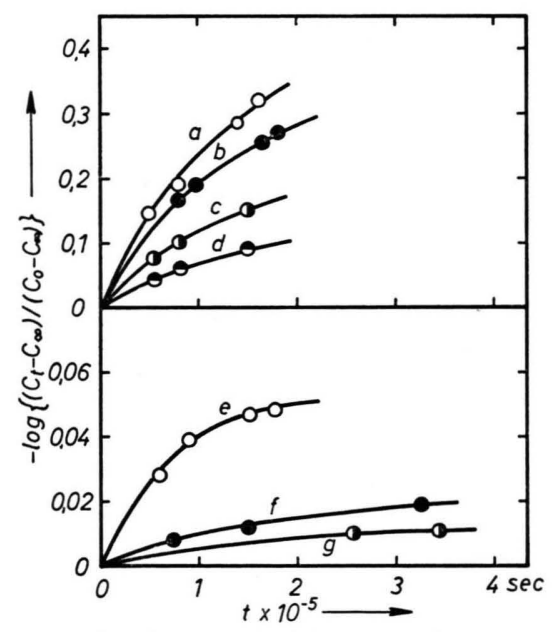

Fig. 3. Relationship between $\log \left[\left(C_{t}-C_{\infty}\right) /\left(C_{0}-C_{\infty}\right)\right]$ and $t$. a: at $650{ }^{\circ} \mathrm{C} ;$ b: at $601{ }^{\circ} \mathrm{C}$; c: at $552^{\circ} \mathrm{C}$; d: at $501{ }^{\circ} \mathrm{C}$; e: at $452{ }^{\circ} \mathrm{C}$; f: at $405{ }^{\circ} \mathrm{C}$; g: at $351{ }^{\circ} \mathrm{C}$. every temperature. Therefore, it has been reconfirm. ed that the rate-determining step was not the exchange reaction, but the diffusion process.

The experimental results are shown in Fig. 4 and Equation (3). The Arrhenius equation was applicable to this diffusion process.

$$
D=2.49 \times 10^{-2} \exp \{-(32800 \pm 8000) / R T\}
$$

with $D$ in $\mathrm{cm}^{2} / \mathrm{sec}$ and $R T$ in cal $/ \mathrm{mol}$.

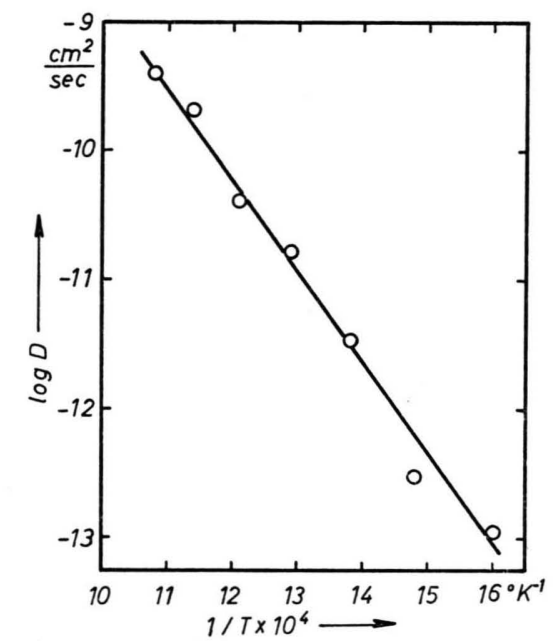

Fig. 4. Relationship between $\log D\left(\mathrm{~cm}^{2} / \mathrm{sec}\right)$ and $(1 / T) \times 10^{4}\left({ }^{\circ} \mathrm{K}^{-1}\right)$.

When the diffusion rate is measured with the gasliquid isotope exchange method, displacement of the exchange surface due to vaporization of boron trioxide during the experiment must be considered. But in this study, the experiment was carried out at temperatures between $351{ }^{\circ} \mathrm{C}$ and $650{ }^{\circ} \mathrm{C}$. At these temperatures, the vapor pressure of boron trioxide is about $10^{-9}-10^{-10} \mathrm{Torr}^{4}$, and the vaporization rate will be so slow that displacement of the gasliquid isotope exchange surface is expected to be negligible. Experimentally, the weight loss during the experiment was not detected with a chemical balance. Therefore, the effect of boundary surface displacement on the calculation of diffusion coefficients was neglected.

It is a well known fact that boron trioxide contains a small amount of water even when dried at several hundred degrees centigrade. According to

${ }^{4}$ R. Speiser, S. Noiditch, and H. L. Thomson, J. Amer. Chem. Soc. 72, 2578 [1950]. 
viscosity measurements ${ }^{5-11}$, the water content decreases to $0.1-0.2 \mathrm{~mol}-\%$ at $1100^{\circ}-1200^{\circ} \mathrm{C}$, and the equilibrium is reached. The time to attain equilibrium is considerably decreased by inert gas bubbling. Bubbling for $15-20 \mathrm{hr}$ at $1200{ }^{\circ} \mathrm{C}$ is enough to get a constant viscosity.

We found that $D \mathrm{~cm}^{2} / \mathrm{sec}$ decreased from 1.23 $\times 10^{-10}$ to $5.27 \times 10^{-11}$ when dehydration at $800{ }^{\circ} \mathrm{C}$ was prolonged from 2.0 to $11.6 \mathrm{hr}$, and that it decreased from $2.16 \times 10^{-11}$ to $1.67 \times 10^{-11}$ when dehydration at $1200^{\circ} \mathrm{C}$ was prolonged from 10.4 to 22.5 hours. It was concluded that $10 \mathrm{hr}$ bubbling at $1200{ }^{\circ} \mathrm{C}$ was enough to get constant diffusion coefficients.

5 A. Napolitano, P. B. Macedo, and E. G. Hawkins, J. Amer. Ceram. Soc. 48, 613 [1965].

6 J. D. Mackenzie, J. Phys. Chem. 63, 1875 [1959].

7 J. D. Mackenzie, Trans. Faraday Soc. 52. 1564 [1956].

8 Pei-Ching Li, A. C. Ghose, and Gong-Jen Su, J. Amer. Ceram. Soc. 45, 89 [1962].

\section{Discussion}

Crystalline boron trioxide has a layer structure ${ }^{12}$. Molten boron trioxide is supposed to be an assembly of irregular curvilinear atomic planes which have many broken bonds. Transfer of an atomic chain from one atomic plane which it breaks away from, to another where new bonds are made, will be the elementary process of the self diffusion in a glassformer melt such as molten boron trioxide.

The energy of activation for self diffusion was found to be about $1 / 3$ of the bond energy between the boron atom and the oxygen atom, and about $2 / 5$ of the heat of vaporization.

9 E. F. Riebling, J. Amer. Ceram. Soc. 49, 19 [1966].

10 R. A. Eppler, J. Amer. Ceram. Soc. 49, 679 [1966].

11 J. Boow, Phys. Chem. Glasses 8, 45 [1967].

12 F. Herre and H. Richter, Z. Naturforsch. 12 a. 545 [1957]. 